Article

\title{
Tunable Electronic Properties of Nitrogen and Sulfur Doped Graphene: Density Functional Theory Approach
}

\author{
Ji Hye Lee ${ }^{1}$, Sung Hyun Kwon ${ }^{1}$, Soonchul Kwon ${ }^{2}$, Min Cho ${ }^{3}$, Kwang Ho Kim ${ }^{4}$, \\ Tae Hee Han ${ }^{5, *}$ (D) and Seung Geol Lee ${ }^{1, *}$ \\ 1 Department of Organic Material Science and Engineering, Pusan National University, 2, \\ Busandaehak-ro 63beon gil, Geumjeong-gu, Busan 46241, Korea; iciti5425@pusan.ac.kr (J.H.L.); \\ rnjstjdgus5@hanmail.net (S.H.K.) \\ 2 Department of Civil and Environmental Engineering, Pusan National University, 2, \\ Busandaehak-ro 63beon gil, Geumjeong-gu, Busan 46241, Korea; sckwon@pusan.ac.kr \\ 3 Division of Biotechnology, Advanced institute of Environment and Bioscience, College of Environmental \\ and Bioresource Sciences, Chonbuk National University, Iksan 54596, Korea; cho317@jbnu.ac.kr \\ 4 School of Materials Science and Engineering, Pusan National University, 2, Busandaehak-ro 63 Beon-gil, \\ Geumjeong-gu, Busan 46241, Korea; khkim@pusan.ac.kr \\ 5 Department of Organic and Nano Engineering, Hanyang University, Seoul 04763, Korea \\ * Correspondence: than@hanyang.ac.kr (T.H.H.); seunggeol.lee@pusan.ac.kr (S.G.L.)
}

Received: 7 January 2019; Accepted: 13 February 2019; Published: 15 February 2019

\begin{abstract}
We calculated the band structures of a variety of N- and S-doped graphenes in order to understand the effects of the $\mathrm{N}$ and $\mathrm{S}$ dopants on the graphene electronic structure using density functional theory (DFT). Band-structure analysis revealed energy band upshifting above the Fermi level compared to pristine graphene following doping with three nitrogen atoms around a mono-vacancy defect, which corresponds to p-type nature. On the other hand, the energy bands were increasingly shifted downward below the Fermi level with increasing numbers of $S$ atoms in N/S-co-doped graphene, which results in n-type behavior. Hence, modulating the structure of graphene through $\mathrm{N}$ - and S-doping schemes results in the switching of "p-type" to "n-type" behavior with increasing $\mathrm{S}$ concentration. Mulliken population analysis indicates that the $\mathrm{N}$ atom doped near a mono-vacancy is negatively charged due to its higher electronegativity compared to $\mathrm{C}$, whereas the $\mathrm{S}$ atom doped near a mono-vacancy is positively charged due to its similar electronegativity to $\mathrm{C}$ and its additional valence electrons. As a result, doping with $\mathrm{N}$ and $\mathrm{S}$ significantly influences the unique electronic properties of graphene. Due to their tunable band-structure properties, the resulting Nand S-doped graphenes can be used in energy and electronic-device applications. In conclusion, we expect that doping with $\mathrm{N}$ and $\mathrm{S}$ will lead to new pathways for tailoring and enhancing the electronic properties of graphene at the atomic level.
\end{abstract}

Keywords: co-doping; graphene; electronic structure; density functional theory; tunable electronics

\section{Introduction}

Graphene consists of two-dimensional sheets of $\mathrm{sp}^{2}$-bonded carbon atoms arranged in a honeycomb lattice [1-3]. It is a zero bandgap semiconductor or semimetal with a large surface area of $2630 \mathrm{~m}^{2} \mathrm{~g}^{-1}[4,5]$, which is larger than other carbon-based materials [5,6]. Graphene also has exceptional charge-carrier mobility of $2 \times 10^{5} \mathrm{~cm}^{2} \mathrm{~V} \mathrm{~s}^{-1}$ [7], good thermal conductivity of $\sim 5000 \mathrm{~W} \mathrm{~m}^{-1} \mathrm{~K}^{-1}$ [8] and high mechanical strength with $\sim 1$ TPa of Young's modulus [9]. Due to its fascinating properties, graphene is considered to be a promising candidate material for applications in 
a wide range of fields, such as nanoelectronics [10], optoelectronics [11], energy-storage and conversion devices [12-14], sensors [15], and catalysts [16]. It is essential that the intrinsic electronic properties of graphene are tailorable for use in a range of nanoelectronics devices. Tremendous effort has been dedicated to the tuning of the electronic properties of graphene, and various techniques have been proposed [17-33]. As the zero bandgap, at the Fermi level, is attributed to the sub-lattice symmetry of the graphene structure, breaking this symmetry will induce bandgap widening. Substitutional doping and the formation of atomistic defects such as vacancies are simple and effective methods for opening the bandgap and altering the band structure of graphene. The band structure can subsequently be tuned by controlling the degree of heteroatom doping or the number of vacancies. The electronic properties of graphene have been found to change considerably when doped with single heteroatoms, such as $\mathrm{B}$, $\mathrm{N}, \mathrm{O}, \mathrm{P}$, or S [17-19,23,24,28-30,33]. Because of the relative differences in the electronegativities of the atomic dopants with respect to that of $\mathrm{C}$, heteroatom doping is expected to induce changes in the band structure, charge distribution, and magnetic properties of graphene. Both experimental and theoretical studies have revealed that graphitic $\mathrm{N}$ atoms lead to $\mathrm{n}$-type behavior, whereas pyridinic and pyrrolic $\mathrm{N}$ atoms give rise to p-type behavior [22-24]. Therefore, controlling the bonding configurations of the $\mathrm{N}$ atoms in graphene may provide a mechanism for tuning the electronic characteristics from n-type to p-type. Recently, co-doping with multiple heteroatoms has become popular because co-doping creates a unique, synergistically coupled, electronic structure. However, there are few reports that provide a fundamental understanding of the alternating electronic structure and accompanying performance of co-doped graphene [25-28,31-33]. Among the atoms possible as $\mathrm{N}$ co-dopants, the $\mathrm{S}$ atom is considered to be an attractive doping material due to its similar electronegativity and van der Waals radius to those of $C$, while possessing two lone pairs of electrons. Herein, we present a spin-polarized density functional theory (DFT) study on the electronic properties of $\mathrm{N}$ - and S-doped graphene in which we characterize changes in band structure and charge-density distribution by controlling the concentrations of the $\mathrm{N}$ and $\mathrm{S}$ dopants.

\section{Computational Details}

First-principles density functional theory (DFT) calculations were carried out using the Vienna $\mathrm{Ab}$ Initio Simulation Package (VASP) [34,35]. Geometries were optimized, and the total energies and forces were calculated using a planewave basis set with the projector augmented wave (PAW) method [36]. The generalized gradient approximation (GGA) with the Perdew-Burke-Ernzerhof (PBE) exchange-correlation functional [37] was used, and the planewave cutoff energy was set to $500 \mathrm{eV}$; the GGA-PBE functional has been successfully used to describe carbon-based systems [38-43]. All structures were optimized such that the total energy converged to less than $1.0 \times 10^{-6} \mathrm{eV}$ per atom and the maximum force converged to below $0.05 \mathrm{eV}^{-1}$. The graphene model used in our simulation consisted of a $12.3 \times 12.3 \times 15.0 \AA, 5 \times 5$ supercell with a vacuum thickness of $15 \AA$, which avoids interference between adjacent graphene layers. Brillouin-zone integrations were carried out using a $4 \times 4 \times 1$ Monkhorst-Pack K-point grid. The effects of van der Waals (vdW) interactions were included using the empirical DFT-D3 correction within the Grimme scheme [44]. All atomic charge distributions in our study were calculated by Mulliken population analysis from Materials Studio $[45,46]$.

\section{Results and Discussion}

Various configurations exist for the doped and defective graphene chosen as the anode material in a lithium-ion battery (LIB). For instance, $\mathrm{N}$-doped graphene exists in distinct forms that include graphitic, pyridinic, and pyrrolic $\mathrm{N}$ atoms [47]. Among these nitrogen types, pyridinic N-doped graphene is believed to be associated with high electrocatalytic activity and excellent reversible capacity $[29,48,49]$. Pyridinic Ns are located at the edges of graphene planes, and arise from $\mathrm{sp}^{2}$-hybridized $\mathrm{N}$ atoms bonded to two neighboring $\mathrm{sp}^{2}$-hybridized $\mathrm{C}$ atoms. Using this configuration as the starting point, different configurations of $\mathrm{N}$ - and S-doped graphene with mono-vacancy defects 
were built as simulation models. Three $\mathrm{C}$ atoms around a mono-vacancy defect were substituted with different numbers of atomic N and/or S dopants. Regarding model structures in this investigation, research groups successfully reported the synthesis of $\mathrm{N}$ - and S-doped graphene [22,43,50-64]. In order to analyze the effects of the $\mathrm{N}$ and $\mathrm{S}$ doping levels on electronic properties, we first fixed the doping concentration to three dopant atoms at the mono-vacancy defect. We constructed four configurations with different $\mathrm{N}$ and $\mathrm{S}$ doping ratios; the graphene doped with three nitrogen atoms is designated as "3N-gra", that doped with two nitrogens and one sulfur as "2N1S-gra", while the graphene doped with one nitrogen and two sulfur atoms is "1N2S-gra", and the three sulfur-doped graphene is "3S-gra". The optimized structures of the N- and S-doped graphenes are displayed in Figure 1, with the calculated band structures shown in Figure 2, which reveal clear changes in electronic structure following doping with $\mathrm{N}$ and S. Pristine graphene is a zero bandgap semiconductor with its Dirac point located at the Fermi energy [38].

a

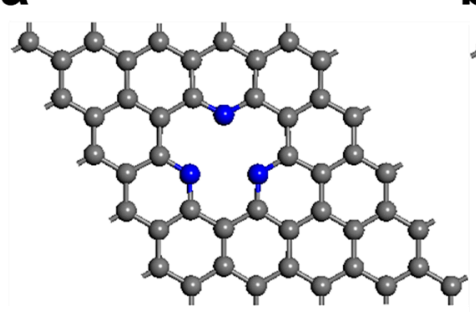

c

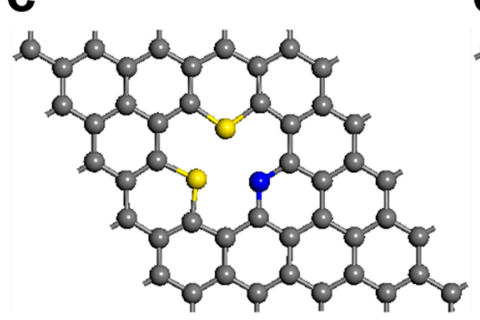

b

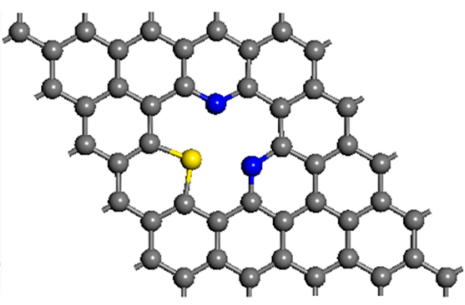

d

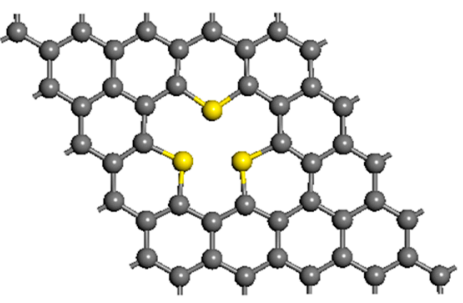

Figure 1. Optimized structures of the (a) 3N-gra, (b) 2N1S-gra, (c) 1N2S-gra, and (d) 3S-gra systems. Blue, gray, and yellow denote nitrogen, carbon, and sulfur, respectively.

a

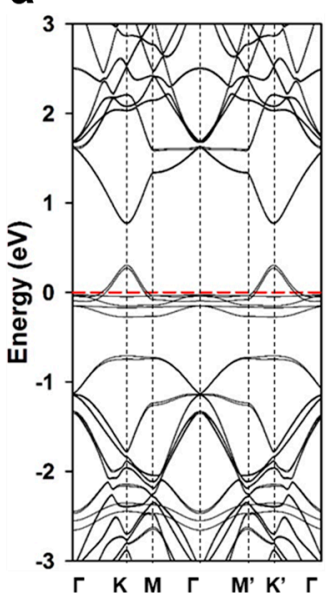

b

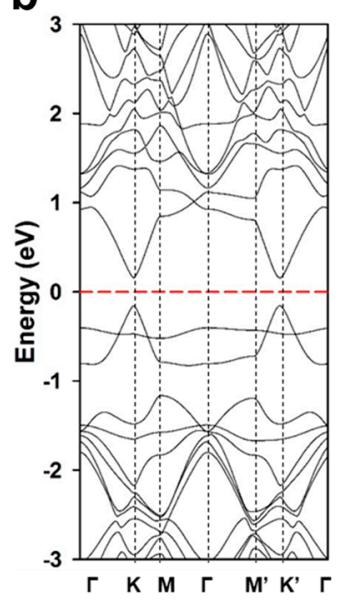

$\mathbf{C}_{3}$

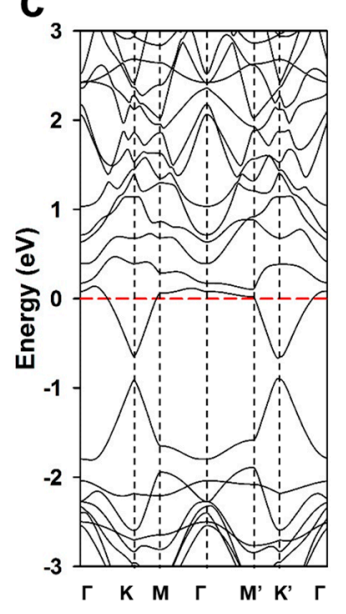

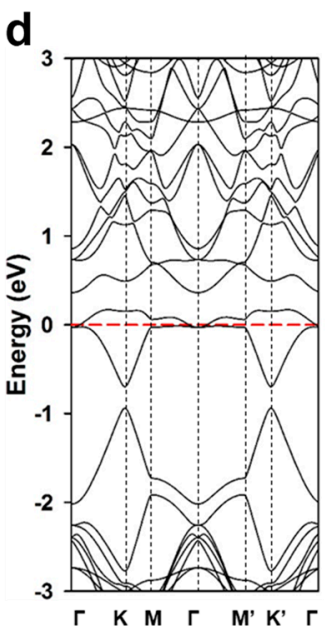

Figure 2. Calculated band structures of the (a) 3N-gra, (b) 2N1S-gra, (c) 1N2S-gra, and (d) 3S-gra systems.

The bandgap clearly opens after doping with $\mathrm{N}$ or $\mathrm{S}$, and/or the introduction of a mono-vacancy defect, which is ascribable to the effects of the atomic dopant and/or vacancy defect on the $\pi$ electrons 
in the hexagonal rings. Mono-vacancy defects lead to shortages of whole charges compared to pristine graphene, which downshift the Fermi energy, indicating that the mono-vacancy defect acts as a hole dopant with missing $\pi$ electrons. As shown in Figure S1, the band structure for pristine graphene and graphene with a single vacancy were calculated that the band gap of graphene with a single vacancy is opened at the Dirac point and the Fermi level is downshifted compared to pristine graphene.

On the other hand, $\mathrm{N}$ and $\mathrm{S}$ atoms have one and two additional valence electrons, respectively; hence, doping with $\mathrm{N}$ or $\mathrm{S}$ results in an upward shift in the Fermi energy. Table 1 reveals that the bandgap energies also change when the band structures are altered by the atomic dopant and/or vacancy defect. In moving from 3N-gra to 3S-gra, the bandgap energy was observed to gradually decrease with increasing levels of the sulfur dopant. The Fermi level is substantially shifted downward from the Dirac point of pristine graphene in 3N-gra. This downward shift indicates that the 3N-doped graphene exhibits p-type behavior and has an affinity for gaining electron density. In addition, flat bands appeared around the Fermi level. Meanwhile, the Fermi level for 3N-doped graphene is somewhat upshifted compared to the mono-vacancy defective graphene because nitrogen has more available electrons than carbon and can replenish some of the electron deficiency. Nevertheless, doping the mono-vacancy defective graphene with three $\mathrm{N}$ atoms is unable to completely compensate for the charge deficiency of the mono-vacancy defect. The energy band gradually becomes narrower, that is to say, the Fermi level is upshifted in moving from 3N-gra to 3S-gra, with increasing levels of the sulfur dopant. Indeed, the energy band for 2N1S-gra is slightly narrower than that of the 3N-gra system. In addition, the band structure of the 1NS2-gra system, which is more doped with sulfur than nitrogen, features visible changes in band energies that are shifted below the Fermi level; hence, this system can be considered to exhibit n-type behavior. Interestingly, the p-type to n-type conversion can be induced through control of the $\mathrm{N}$ and S doping levels (e.g., by increasing the S-to-N doping ratio). The 3S-gra system also exhibits n-type character, with slightly downward shifted band energies compared to the 1N2S-gra system; however, the level of downward shift induced by moving from 1N2S-gra to S3-gra is very marginal. The degree in the downward shift in band energy tends to decrease with decreasing nitrogen atom concentration.

Table 1. The band gap energies Eg (in eV) for 3N-gra, 2N1S-gra, 1N2S-gra and 3S-gra systems.

\begin{tabular}{lcccc}
\hline & 3N-gra & 2N1S-gra & 1N2S-gra & 3S-gra \\
\hline Bandgap $(\mathrm{eV})$ & 0.473 & 0.350 & 0.275 & 0.255 \\
\hline
\end{tabular}

Finally, we studied the charge-density distribution of each atom around the mono-vacancy defect for each $\mathrm{N}$ - and S-doped graphene system by Mulliken population analysis because the charge distributions on the carbon, nitrogen, and sulfur atoms are important for determining the origin of the alternating electronic properties. Figure 3 displays the charge on each atom around the mono-vacancy defect; positive charges are shown in black, while negative charges are shown in red. The difference in the electronegativity of the $\mathrm{N}$ atom (3.04) and the $\mathrm{C}$ atom (2.55), which is referred to Pauling scale [65], polarizes the hexagonal ring. Therefore, all of the $\mathrm{N}$ atoms inside the mono-vacancy for each system are negatively charged. The average charges on the $\mathrm{N}$ atoms in these systems were determined to be $-0.176 \mathrm{e},-0.341 \mathrm{e}$, and $-0.401 \mathrm{e}$ for 3N-gra, 2N1S-gra, and 1N2S-gra, respectively. Meanwhile, most of the compensating positive charges are distributed on the adjacent $C$ atoms connected to the atomic $\mathrm{N}$ dopants. As shown in Figure 2a (3N-gra system), the charges on the three $\mathrm{C}$ atoms connected to the $\mathrm{N}$ atoms in the range between +0.043 and $+0.044 \mathrm{e}$. Unlike the $\mathrm{N}$-doped systems, the $C-S$ bond is negligibly polarized because the electronegativities of the $S(2.58)$ and $C(2.55)$ atoms are similar. Moreover, the $\mathrm{S}$ atom has two additional valence electrons compared to carbon, which provide positive charge and lone pairs of electrons. The average charges on the $S$ atoms in these systems were determined to be $+0.475 \mathrm{e},+0.374 \mathrm{e}$, and $+0.302 \mathrm{e}$ for $2 \mathrm{~N} 1 \mathrm{~S}-$ gra, $1 \mathrm{~N} 2 \mathrm{~S}-$ gra, and $3 \mathrm{~S}-$ gra, respectively. In contrast, most of the compensating negative charges are distributed on the adjacent $C$ atoms bonded to the doping $S$ atoms. As displayed in Figure $2 b$ (the 2N1S-gra system), the $C$ atoms 
bonded to the $\mathrm{N}$ atoms bear positive charges, with values of $+0.081 \mathrm{e}$ and $+0.146 \mathrm{e}$ on the $\mathrm{C}_{\mathrm{N} 1}{ }^{\prime}$ and $\mathrm{C}_{\mathrm{N} 1}{ }^{\prime \prime}$ atoms, and $+0.143 \mathrm{e}$ and $+0.082 \mathrm{e}$ on the $\mathrm{C}_{\mathrm{N} 2}{ }^{\prime}$ and $\mathrm{C}_{\mathrm{N} 2}{ }^{\prime \prime}$ atoms, respectively. The charges on the $\mathrm{C}$ atoms on each side of the $\mathrm{N}$ atom are almost identical. On the other hand, the $\mathrm{C}$ atoms bonded to the $S$ atom exhibit negative charges, at $-0.242 \mathrm{e}$ on $\mathrm{C}_{\mathrm{S} 1}{ }^{\prime}$, and $-0.246 \mathrm{e}$ on $\mathrm{C}_{\mathrm{S} 1}{ }^{\prime \prime}$. Likewise, the $1 \mathrm{~N} 2 \mathrm{~S}$-gra system showed a similar trend. As shown in Figure $2 c$, the $C$ atoms bonded to the $\mathrm{N}$ atoms, namely $\mathrm{C}_{\mathrm{N} 1}{ }^{\prime}$ and $\mathrm{C}_{\mathrm{N} 2}{ }^{\prime \prime}$, bear charges of $+0.109 \mathrm{e}$ and $+0.110 \mathrm{e}$, which are almost identical. The $\mathrm{C}$ atoms adjacent to the $S$ atoms exhibit negative charges, with charges of $-0.248 \mathrm{e}$ and $-0.240 \mathrm{e}$ on $\mathrm{C}_{\mathrm{S} 1}{ }^{\prime}$ and $\mathrm{C}_{\mathrm{S} 1}{ }^{\prime \prime}$, and $-0.238 \mathrm{e}$ and $-0.250 \mathrm{e}$ on the $\mathrm{C}_{\mathrm{S} 2}{ }^{\prime}$ and $\mathrm{C}_{\mathrm{S} 2}{ }^{\prime \prime}$ atoms, respectively. Finally, the 3S-gra system exhibited charges on the $C$ atoms bonded to the $S$ atoms that were in the -0.245 e to -0.233 e range. It seems that polarization in the doped region increases with increasing $S$ concentration. The transformed charge-density distribution following doping, as well as the vacancy defect, affects the electronic properties of the graphene system.

a

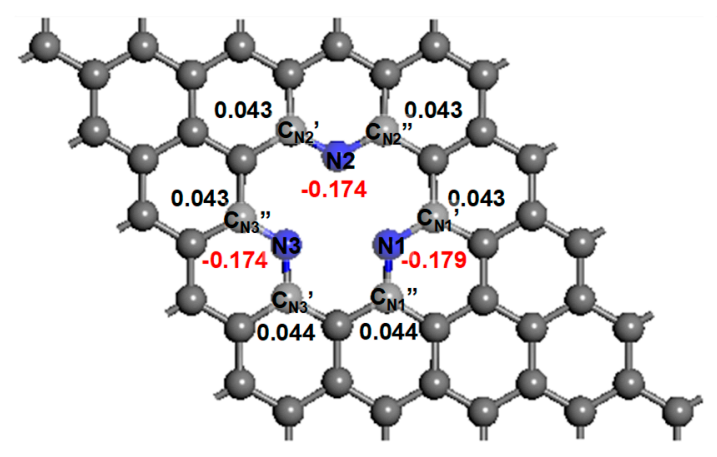

b

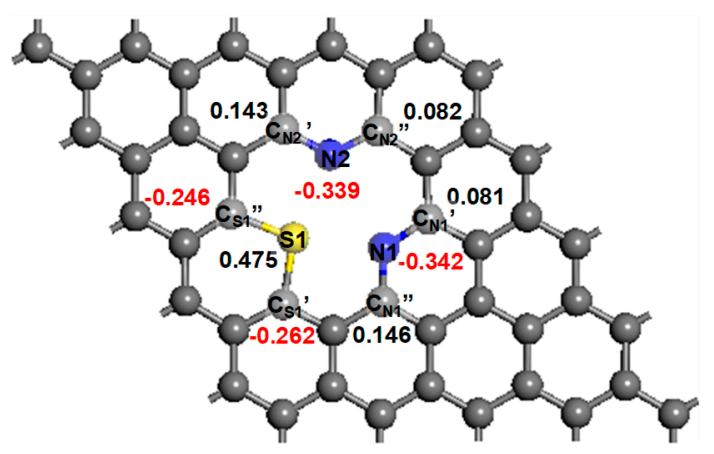

d

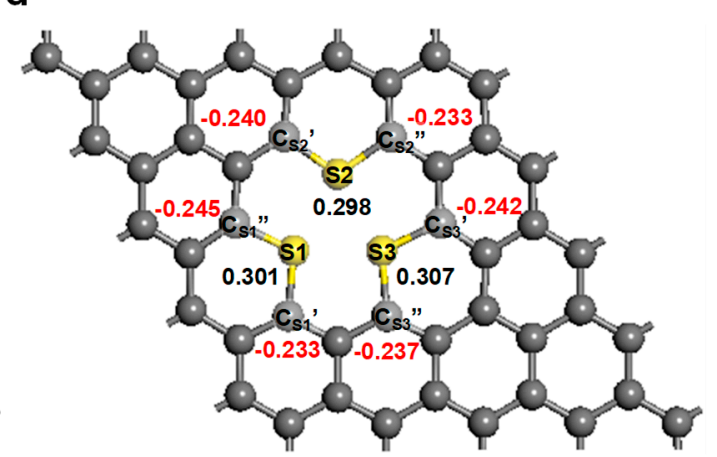

Figure 3. Calculated charge-density distributions on the atoms around the doped mono-vacancy region for the (a) 3N-gra, (b) 2N1S-gra, (c) 1N2S-gra, and (d) 3S-gra systems. Blue, gray, and yellow denote nitrogen, carbon, and sulfur, respectively.

\section{Conclusions}

The present density functional theory study aimed to reveal details of the electronic structures of several N- and S-doped graphenes in order to understand the effects of the $\mathrm{N}$ and S dopants on the graphene electronic structure. We found that the band structure of graphene can easily be tuned by doping with $\mathrm{N}$ and $\mathrm{S}$ atoms. The roles of the atomic $\mathrm{N}$ and $\mathrm{S}$ dopants on the band energies were clearly revealed; these dopants noticeably perturb the band shapes and open the bandgap at the Dirac point, compared to graphene itself. The band energies of 3N-doped graphene were upward shifted below the Fermi level compared with those of pure graphene, and showed p-type behavior. The band structure exhibits a remarkable electronic transition, from "p-type" to "n-type", in moving from 3N-gra to 3S-gra (with increasing numbers of S atoms) with a downshifting of the band energy below the Fermi level. Moreover, Mulliken population analysis revealed that the atomic $\mathrm{N}$ dopants bear negative 
charges, whereas the atomic S dopants bear positive charges in N- and/or S-co-doped graphene systems, which is ascribable to differences in the electronegativities and numbers of valence electrons among the $\mathrm{C}, \mathrm{N}$, and $\mathrm{S}$ atoms. In each $\mathrm{N}$ - and/or S-co-doped graphene system, all of the $\mathrm{N}$ atoms bear negative charges, whereas all of the $\mathrm{S}$ atoms bear positive charges. The average charge on the $\mathrm{N}$ atoms gradually increases with decreasing numbers of $\mathrm{N}$ atoms in the $\mathrm{N}$ - and / or S-co-doped graphene system. In contrast, the average charge on the $S$ atoms decreases with increasing numbers of $S$ atoms in the co-doped graphene system. Due to their tunable band-structure properties, the resulting $\mathrm{N}$ - and S-co-doped graphenes can be used in energy and electronic-device applications. In conclusion, we expect that doping with $\mathrm{N}$ and $\mathrm{S}$ will lead to new pathways for tailoring and enhancing the electronic properties of graphene at the atomic level.

Supplementary Materials: The following are available online at http:/ /www.mdpi.com/2079-4991/9/2/268/s1, Figure S1: Calculated band structures of the (a) pristine graphene and (b) graphene with mono-vacancy.

Author Contributions: S.G.L., K.H.K., and T.H.H. conceived the research idea. J.H.L, S.K., M.C., and S.G.L. wrote the main manuscript text. J.H.L. and S.H.K. performed the experiments. All authors reviewed the manuscript.

Funding: This research was funded by the National Research Foundation of Korea (NRF) funded by the Ministry of Science, ICT \& Future Planning (Nos. NRF-2016M1A2A2937151 and NRF-2016R1A6A1A03013422). This research was funded by the Global Frontier Program through the Global Frontier Hybrid Interface Materials (GFHIM) of the NRF of Korea funded by the Ministry of Science, ICT, and Future Planning (No. 2013M3A6B1078882).

Acknowledgments: This research was supported by the National Research Foundation of Korea (NRF) funded by the Ministry of Science, ICT \& Future Planning (Nos. NRF-2016M1A2A2937151 and NRF-2016R1A6A1A03013422). This research was supported by the Global Frontier Program through the Global Frontier Hybrid Interface Materials (GFHIM) of the NRF of Korea funded by the Ministry of Science, ICT, and Future Planning (No. 2013M3A6B1078882)

Conflicts of Interest: The authors declare no conflict of interest.

\section{References}

1. Geim, A.K.; Novoselov, K.S. The rise of graphene. Nat. Mater. 2007, 6, 183-191. [CrossRef] [PubMed]

2. $\quad$ Castro Neto, A.H.; Guinea, F.; Peres, N.M.R.; Novoselov, K.S.; Geim, A.K. The electronic properties of graphene. Rev. Modern Phys. 2009, 81, 109-162. [CrossRef]

3. Geim, A.K. Graphene: Status and Prospects. Science 2009, 324, 1530-1534. [CrossRef] [PubMed]

4. Stankovich, S.; Dikin, D.A.; Dommett, G.H.B.; Kohlhaas, K.M.; Zimney, E.J.; Stach, E.A.; Piner, R.D.; Nguyen, S.T.; Ruoff, R.S. Graphene-based composite materials. Nature 2006, 442, 282-286. [CrossRef] [PubMed]

5. Peigney, A.; Laurent, C.; Flahaut, E.; Bacsa, R.R.; Rousset, A. Specific surface area of carbon nanotubes and bundles of carbon nanotubes. Carbon 2001, 39, 507-514. [CrossRef]

6. Zhu, Y.W.; Murali, S.; Stoller, M.D.; Ganesh, K.J.; Cai, W.W.; Ferreira, P.J.; Pirkle, A.; Wallace, R.M.; Cychosz, K.A.; Thommes, M.; et al. Carbon-Based Supercapacitors Produced by Activation of Graphene. Science 2011, 332, 1537-1541. [CrossRef] [PubMed]

7. Bolotin, K.I.; Sikes, K.J.; Jiang, Z.; Klima, M.; Fudenberg, G.; Hone, J.; Kim, P.; Stormer, H.L. Ultrahigh electron mobility in suspended graphene. Solid State Commun. 2008, 146, 351-355. [CrossRef]

8. Balandin, A.A.; Ghosh, S.; Bao, W.Z.; Calizo, I.; Teweldebrhan, D.; Miao, F.; Lau, C.N. Superior thermal conductivity of single-layer graphene. Nano Lett. 2008, 8, 902-907. [CrossRef]

9. Lee, C.; Wei, X.D.; Kysar, J.W.; Hone, J. Measurement of the elastic properties and intrinsic strength of monolayer graphene. Science 2008, 321, 385-388. [CrossRef]

10. Freitag, M. Graphene-Nanoelectronics goes flat out. Nat. Nanotechnol. 2008, 3, 455-457. [CrossRef]

11. Bonaccorso, F.; Sun, Z; Hasan, T.; Ferrari, A.C. Graphene photonics and optoelectronics. Nat. Photon. 2010, 4, 611-622. [CrossRef]

12. Hou, J.B.; Shao, Y.Y.; Ellis, M.W.; Moore, R.B.; Yi, B.L. Graphene-based electrochemical energy conversion and storage: Fuel cells, supercapacitors and lithium ion batteries. Phys. Chem. Chem. Phys. 2011, 13, 15384-15402. [CrossRef] [PubMed]

13. Choi, H.J.; Jung, S.M.; Seo, J.M.; Chang, D.W.; Dai, L.M.; Baek, J.B. Graphene for energy conversion and storage in fuel cells and supercapacitors. Nano Energy 2012, 1, 534-551. [CrossRef] 
14. Bonaccorso, F.; Colombo, L.; Yu, G.H.; Stoller, M.; Tozzini, V.; Ferrari, A.C.; Ruoff, R.S.; Pellegrini, V. Graphene, related two-dimensional crystals, and hybrid systems for energy conversion and storage. Science 2015, 347, 1246501. [CrossRef] [PubMed]

15. Shao, Y.Y.; Wang, J.; Wu, H.; Liu, J.; Aksay, I.A.; Lin, Y.H. Graphene Based Electrochemical Sensors and Biosensors: A Review. Electroanalysis 2010, 22, 1027-1036. [CrossRef]

16. Huang, C.C.; Li, C.; Shi, G.Q. Graphene based catalysts. Energy Environ. Sci. 2012, 5, 8848-8868. [CrossRef]

17. Liu, H.T.; Liu, Y.Q.; Zhu, D.B. Chemical doping of graphene. J. Mater. Chem. 2011, 21, 3335-3345. [CrossRef]

18. Nigar, S.; Zhou, Z.F.; Wang, H.; Imtiaz, M. Modulating the electronic and magnetic properties of graphene. RSC Adv. 2017, 7, 51546-51580. [CrossRef]

19. Wang, X.W.; Sun, G.Z.; Routh, P.; Kim, D.H.; Huang, W.; Chen, P. Heteroatom-doped graphene materials: Syntheses, properties and applications. Chem. Soc. Rev. 2014, 43, 7067-7098. [CrossRef]

20. Liu, L.L.; Qing, M.Q.; Wang, Y.B.; Chen, S.M. Defects in Graphene: Generation, Healing, and Their Effects on the Properties of Graphene: A Review. J. Mater. Sci. Technol. 2015, 31, 599-606. [CrossRef]

21. Banhart, F.; Kotakoski, J.; Krasheninnikov, A.V. Structural Defects in Graphene. ACS Nano 2011, 5, $26-41$. [CrossRef] [PubMed]

22. Schiros, T.; Nordlund, D.; Palova, L.; Prezzi, D.; Zhao, L.Y.; Kim, K.S.; Wurstbauer, U.; Gutierrez, C.; Delongchamp, D.; Jaye, C.; et al. Connecting Dopant Bond Type with Electronic Structure in N-Doped Graphene. Nano Lett. 2012, 12, 4025-4031. [CrossRef] [PubMed]

23. Fujimoto, Y.; Saito, S. Formation, stabilities, and electronic properties of nitrogen defects in graphene. Phys. Rev. B 2011, 84, 245446. [CrossRef]

24. Hou, Z.F.; Wang, X.L.; Ikeda, T.; Terakura, K.; Oshima, M.; Kakimoto, M. Electronic structure of N-doped graphene with native point defects. Phys. Rev. B 2013, 87, 165401. [CrossRef]

25. Wang, T.; Wang, L.X.; Wu, D.L.; Xia, W.; Jia, D.Z. Interaction between Nitrogen and Sulfur in Co-Doped Graphene and Synergetic Effect in Supercapacitor. Sci. Rep. 2015, 5, 9591. [CrossRef]

26. Xu, J.X.; Dong, G.F.; Jin, C.H.; Huang, M.H.; Guan, L.H. Sulfur and Nitrogen Co-Doped, Few-Layered Graphene Oxide as a Highly Efficient Electrocatalyst for the Oxygen-Reduction Reaction. ChemSusChem 2013, 6, 493-499. [CrossRef]

27. Wu, Z.S.; Winter, A.; Chen, L.; Sun, Y.; Turchanin, A.; Feng, X.L.; Mullen, K. Three-Dimensional Nitrogen and Boron Co-doped Graphene for High-Performance All-Solid-State Supercapacitors. Adv. Mater. 2012, 24, 5130-5135. [CrossRef]

28. Panchokarla, L.S.; Subrahmanyam, K.S.; Saha, S.K.; Govindaraj, A.; Krishnamurthy, H.R.; Waghmare, U.V.; Rao, C.N.R. Synthesis, Structure, and Properties of Boron- and Nitrogen-Doped Graphene. Adv. Mater. 2009, 21, 4726-4730. [CrossRef]

29. Reddy, A.L.M.; Srivastava, A.; Gowda, S.R.; Gullapalli, H.; Dubey, M.; Ajayan, P.M. Synthesis Of Nitrogen-Doped Graphene Films For Lithium Battery Application. ACS Nano 2010, 4, 6337-6342. [CrossRef]

30. Zhang, C.Z.; Mahmood, N.; Yin, H.; Liu, F.; Hou, Y.L. Synthesis of Phosphorus-Doped Graphene and its Multifunctional Applications for Oxygen Reduction Reaction and Lithium Ion Batteries. Adv. Mater. 2013, 25, 4932-4937. [CrossRef]

31. Choi, C.H.; Chung, M.W.; Kwon, H.C.; Park, S.H.; Woo, S.I. B, N- and P, N-doped graphene as highly active catalysts for oxygen reduction reactions in acidic media. J. Mater. Chem. A 2013, 1, 3694-3699. [CrossRef]

32. Ma, X.L.; Ning, G.Q.; Qi, C.L.; Xu, C.G.; Gao, J.S. Phosphorus and Nitrogen Dual-Doped Few-Layered Porous Graphene: A High-Performance Anode Material for Lithium-Ion Batteries. ACS Appl. Mater. Interf. 2014, 6, 14415-14422. [CrossRef] [PubMed]

33. Paraknowitsch, J.P.; Thomas, A. Doping carbons beyond nitrogen: An overview of advanced heteroatom doped carbons with boron, sulphur and phosphorus for energy applications. Energy Environ. Sci. 2013, 6, 2839-2855. [CrossRef]

34. Kresse, G.; Furthmuller, J. Efficient iterative schemes for ab initio total-energy calculations using a plane-wave basis set. Phys. Rev. B 1996, 54, 11169-11186. [CrossRef]

35. Kresse, G.; Furthmuller, J. Efficiency of ab-initio total energy calculations for metals and semiconductors using a plane-wave basis set. Comp. Mater. Sci. 1996, 6, 15-50. [CrossRef]

36. Kresse, G.; Joubert, D. From ultrasoft pseudopotentials to the projector augmented-wave method. Phys. Rev. B 1999, 59, 1758-1775. [CrossRef] 
37. Perdew, J.P.; Burke, K.; Ernzerhof, M. Generalized gradient approximation made simple. Phys. Rev. Lett. 1996, 77, 3865-3868. [CrossRef]

38. Lee, J.H.; Kang, S.G.; Moon, H.S.; Park, H.; Kim, I.T.; Lee, S.G. Adsorption mechanisms of lithium oxides (LixO2) on a graphene-based electrode: A density functional theory approach. App. Surf. Sci. 2015, 351, 193-202. [CrossRef]

39. Pham, N.N.T.; Park, J.S.; Kim, H.-T.; Kim, H.-J.; Son, Y.-A.; Kang, S.G.; Lee, S.G. Catalytic performance of graphene quantum dot supported manganese phthalocyanine for highly efficient oxygen reduction: A DFT+U approach. New J. Chem. 2019, 43, 348-355. [CrossRef]

40. Lee, H.W.; Moon, H.S.; Hur, J.; Kim, I.T.; Park, M.S.; Yun, J.M.; Kim, K.H.; Lee, S.G. Mechanism of sodium adsorption on $\mathrm{N}$-doped graphene nanoribbons for sodium ion battery applications: A density functional theory approach. Carbon 2017, 119, 492-501. [CrossRef]

41. Hwang, D.G.; Jeong, E.; Lee, S.G. Density functional theory study of CH4 and CO2 adsorption by fluorinated graphene. Carbon Lett. 2016, 20, 81-85. [CrossRef]

42. Moon, H.S.; Yun, J.M.; Kim, K.H.; Jang, S.S.; Lee, S.G. Investigations of the band structures of edge-defect zigzag graphene nanoribbons using density functional theory. RSC Adv. 2016, 6, 39587-39594. [CrossRef]

43. Zhang, J.; Yang, Z.X.; Qiu, J.Y.C.; Lee, H.W. Design and synthesis of nitrogen and sulfur co-doped porous carbon via two-dimensional interlayer confinement for a high-performance anode material for lithium-ion batteries. J. Mater. Chem. A 2016, 4, 5802-5809. [CrossRef]

44. Grimme, S.; Antony, J.; Ehrlich, S.; Krieg, H. A consistent and accurate ab initio parametrization of density functional dispersion correction (DFT-D) for the 94 elements H-Pu. J. Chem. Phys. 2010, 132, 154104. [CrossRef] [PubMed]

45. Materials Studio; BIOVIA: San Diego, CA, USA, 2018.

46. Mulliken, R.S. Citation Classic-Electronic Population Analysis on Lcao-Mo Molecular Wave-Functions. Curr. Contents/Eng. Technol. Appl. Sci. 1985, 18.

47. Wang, H.B.; Maiyalagan, T.; Wang, X. Review on Recent Progress in Nitrogen-Doped Graphene: Synthesis, Characterization, and Its Potential Applications. ACS Catal. 2012, 2, 781-794. [CrossRef]

48. Wu, J.J.; Ma, L.L.; Yadav, R.M.; Yang, Y.C.; Zhang, X.; Vajtai, R.; Lou, J.; Ajayan, P.M. Nitrogen-Doped Graphene with Pyridinic Dominance as a Highly Active and Stable Electrocatalyst for Oxygen Reduction. ACS Appl. Mater. Interf. 2015, 7, 14763-14769. [CrossRef]

49. Li, L.J.; Dai, P.C.; Gu, X.; Wang, Y.; Yan, L.T.; Zhao, X.B. High oxygen reduction activity on a metal-organic framework derived carbon combined with high degree of graphitization and pyridinic-N dopants. J. Mater. Chem. A 2017, 5, 789-795. [CrossRef]

50. Sun, D.F.; Yang, J.; Yan, X.B. Hierarchically porous and nitrogen, sulfur-codoped graphene-like microspheres as a high capacity anode for lithium ion batteries. Chem. Commun. 2015, 51, 2134-2137. [CrossRef]

51. Wohlgemuth, S.A.; Vilela, F.; Titirici, M.M.; Antonietti, M. A one-pot hydrothermal synthesis of tunable dual heteroatom-doped carbon microspheres. Green Chem. 2012, 14, 741-749. [CrossRef]

52. Qiu, Z.Z.; Lin, Y.M.; Xin, H.L.; Han, P.; Li, D.Z.; Yang, B.; Li, P.C.; Ullah, S.; Fan, H.S.; Zhu, C.Z.; et al. Ultrahigh level nitrogen/sulfur co-doped carbon as high performance anode materials for lithium-ion batteries. Carbon 2018, 126, 85-92. [CrossRef]

53. Xiong, J.W.; Pan, Q.C.; Zheng, F.H.; Xiong, X.H.; Yang, C.H.; Hu, D.L.; Huang, C.L. N/S Co-doped Carbon Derived From Cotton as High Performance Anode Materials for Lithium Ion Batteries. Front. Chem. 2018, 6, 78. [CrossRef] [PubMed]

54. Ruan, J.F.; Yuan, T.; Pang, Y.P.; Luo, S.N.; Peng, C.X.; Yang, J.H.; Zheng, S.Y. Nitrogen and sulfur dual-doped carbon films as flexible free-standing anodes for Li-ion and Na-ion batteries. Carbon 2018, 126, 9-16. [CrossRef]

55. Wei, T.Y.; Wei, X.L.; Yang, L.W.; Xiao, H.P.; Gao, Y.; Li, H.M. A one-step moderate-explosion assisted carbonization strategy to sulfur and nitrogen dual-doped porous carbon nanosheets derived from camellia petals for energy storage. J. Power Sources 2016, 331, 373-381. [CrossRef]

56. Cai, D.D.; Wang, C.S.; Shi, C.Y.; Tan, N. Facile synthesis of N and S co-doped graphene sheets as anode materials for high-performance lithium-ion batteries. J. Alloys Compd. 2018, 731, 235-242. [CrossRef]

57. Ai, W.; Luo, Z.M.; Jiang, J.; Zhu, J.H.; Du, Z.Z.; Fan, Z.X.; Xie, L.H.; Zhang, H.; Huang, W.; Yu, T. Nitrogen and Sulfur Codoped Graphene: Multifunctional Electrode Materials for High-Performance Li-Ion Batteries and Oxygen Reduction Reaction. Adv. Mater. 2014, 26, 6186-6192. [CrossRef] 
58. Xing, L.B.; Xi, K.; Li, Q.Y.; Su, Z.; Lai, C.; Zhao, X.S.; Kumar, R.V. Nitrogen, sulfur-codoped graphene sponge as electroactive carbon interlayer for high-energy and -power lithium-sulfur batteries. J. Power Sources 2016, 303, 22-28. [CrossRef]

59. Usachov, D.; Vilkov, O.; Gruneis, A.; Haberer, D.; Fedorov, A.; Adamchuk, V.K.; Preobrajenski, A.B.; Dudin, P.; Barinov, A.; Oehzelt, M.; et al. Nitrogen-Doped Graphene: Efficient Growth, Structure, and Electronic Properties. Nano Lett. 2011, 11, 5401-5407. [CrossRef]

60. Yang, Y.F.; Jin, S.; Zhang, Z.; Du, Z.Z.; Liu, H.R.; Yang, J.; Xu, H.X.; Ji, H.X. Nitrogen-Doped Hollow Carbon Nanospheres for High-Performance Li-Ion Batteries. ACS Appl. Mater. Interf. 2017, 9, 14180-14186. [CrossRef]

61. Guo, P.P.; Xiao, F.; Liu, Q.; Liu, H.F.; Guo, Y.L.; Gong, J.R.; Wang, S.; Liu, Y.Q. One-Pot Microbial Method to Synthesize Dual-Doped Graphene and Its Use as High-Performance Electrocatalyst. Sci. Rep. 2013, 3, 3499. [CrossRef]

62. Yang, Z.; Nie, H.G.; Zhou, X.M.; Yao, Z.; Huang, S.M.; Chen, X.H. Investigation of Homologous Series as Precursory Hydrocarbons for Aligned Carbon Nanotube Formation by the Spray Pyrolysis Method. Nano 2011, 6, 205-213. [CrossRef]

63. Ji, J.Y.; Zhang, G.H.; Chen, H.Y.; Wang, S.L.; Zhang, G.L.; Zhang, F.B.; Fan, X.B. Sulfonated graphene as water-tolerant solid acid catalyst. Chem. Sci. 2011, 2, 484-487. [CrossRef]

64. Park, J.E.; Jang, Y.J.; Kim, Y.J.; Song, M.S.; Yoon, S.; Kim, D.H.; Kim, S.J. Sulfur-doped graphene as a potential alternative metal-free electrocatalyst and Pt-catalyst supporting material for oxygen reduction reaction. Phys. Chem. Chem. Phys. 2014, 16, 103-109. [CrossRef] [PubMed]

65. Pauling, L. Citation Classic-The Nature of the Chemical-Bond and the Structure of Molecules and Crystals-An Introduction to Modern Structural Chemistry. Curr. Contents/Phys. Chem. Earth Sci. 1985, 16.

(C) 2019 by the authors. Licensee MDPI, Basel, Switzerland. This article is an open access article distributed under the terms and conditions of the Creative Commons Attribution (CC BY) license (http:/ / creativecommons.org/licenses/by/4.0/). 